\title{
Heterotopia Basilingual Thyroid Goiter: A Case Report
}

\author{
Dahi Mohamed Elmoctar ${ }^{1 *}$, Abdel Vetah Ladour ${ }^{1}$, Cheikh Sidi'1, Lamine Keita1 ${ }^{1}$, S. M. Jiyide1, \\ S. B. Cheikhna', Mariem Aziza Sass ${ }^{1}$, Abdel Moumine¹, Ahmedou Moulaye Idriss², Tfeil Yahya ${ }^{3}$ \\ ${ }^{1}$ ENT Department, CHN Nouakchott, Nouakchott, Mauritania \\ ${ }^{2}$ General Surgery, Surgery Department Faculty of Medicine, Nouakchott, UNA \\ ${ }^{3}$ Urology Department, Faculty of Medicine, Nouakchott, UNA \\ Email: *tardahi1@gmail.com
}

How to cite this paper: Elmoctar, D.M. Ladour, A.V., Sidi, C., Keita, L., Jiyide, S.M., Cheikhna, S.B., Sass, M.A., Moumine, A., Idriss, A.M. and Yahya, T. (2021) Heterotopia Basilingual Thyroid Goiter: A Case Report. International Journal of Otolaryngology and Head \& Neck Surgery, 10, 158-163.

https://doi.org/10.4236/ijohns.2021.103016

Received: March 8, 2021

Accepted: May 14, 2021

Published: May 17, 2021

Copyright (c) 2021 by author(s) and Scientific Research Publishing Inc. This work is licensed under the Creative Commons Attribution International License (CC BY 4.0).

http://creativecommons.org/licenses/by/4.0/

\begin{abstract}
Thyroid heterotopia is an abnormal localization of normal thyroid tissue coexisting with a normal organ and of normal localization. It is distinguished from ectopic thyroid and thyroid cancer metastasis. Lingual or sublingual thyroid is defined as the presence of thyroid tissue in the midline at the base of the tongue anywhere between the circumvallate papillae and the epiglottis. The prevalence of lingual thyroid is 1 in 100,000, and it is more common in women, with a female to male ratio ranging from 3:1 to 7:1. Embryologically, the thyroid originates at the foramen cecum, which is located at the junction of the anterior two thirds with the posterior one-third of the tongue, report a case of a goiter on a heterotopic basilingual thyroid tissue causing dysphagia in a 58-year-old woman operated in the ENT department of the CHN in Nouakchott, Mauritania, the thyroid origin of the mass was confirmed by histology.
\end{abstract}

\section{Keywords}

Basilingual, Goiter, Heterotopia, Nouakchott

\section{Introduction}

Ectopic thyroid is a rare condition [1] [2] [3] [4]. It occurs as a result of a developmental abnormality during migration of the thyroid tubercle from the floor of the primary foregut to its final position in the neck [5], Lingual or sublingual thyroid is defined as the presence of thyroid tissue in the midline at the base of the tongue anywhere between the circumvallate papillae and the epiglottis. The prevalence of lingual thyroid is 1 in 100,000, and it is more common in women, with a female to male ratio ranging from 3:1 to 7:1. Embryologically, the thyroid 
originates at the foramen cecum, which is located at the junction of the anterior two-thirds with the posterior one-third of the tongue [1] [6] [7]. Thyroid heterotopia is an abnormal localization of normal thyroid tissue coexisting with a normal organ and of normal localization [8]. There is no consensus about the optimal therapeutic strategy, perhaps due to the rarity of this clinical entity. Most authors agree that surgical treatment of ectopic thyroid in the neck (mainly lingual, sublingual, submandibular, and lateral cervical) depends on the size and local symptoms (airway obstruction, dysphagia, and dysphonia), as well as on other parameters, such as patient's age, functional thyroid status, and complications of the mass (ulceration, bleeding, cystic degeneration, or malignancy) [5].

We report a case of a goiter on heterotopic basilingual thyroid tissue operated in the ENT department of the CHN in Nouakchott, Mauritania.

\section{Patient and Observation}

This is a 58-year-old female patient with hypertension on treatment, mother of 4 children with a history of uterine fibroma surgery. She consulted in September 2020 for solid dysphagia and feeling of heaviness and fullness in her throat progressively developed since September 2019.

On the history, she did not present in her antecedents any notion of irradiation during childhood, nor of familial history of goiter. She also had no clinical signs of dysthyroidism.

On clinical examination, a reddish mass at the base of the tongue is noted, of firm and well-defined consistency, with a homogeneous smooth surface and not bleeding on contact, taking the valves and coming into contact with the epiglottis (Figure 1). The cervical examination was without abnormality. The CT scan of the neck showed a strongly enhanced tissue mass by injection of contrast product in a homogeneous manner measuring $31 \times 46 \mathrm{~mm}$ infiltrating the base of the tongue and the sublingual space arriving at the bottom in contact with the upper edge of the hyoid bone, occupying the valecules and extending to the level of the HTE space, responsible for a marked narrowing of the oropharynx (Figure 2(a) and Figure 2(b)).

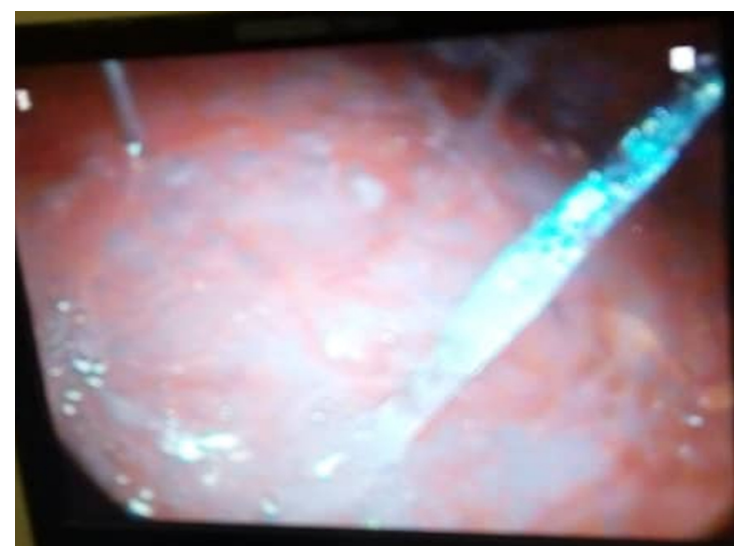

Figure 1. Large reddish mass at the base of the tongue. 
On cervical ultrasound, the thyroid gland was in place and there were no cervical lymph nodes. Thyroid function tests were normal.

Complete excision of the mass was performed via the cervical supra hyoid approach, after a tracheotomy. The pathological examination, sent to two colleagues, concluded that there was basilingual ectopic goiter without signs of malignancy (Figure 3(a) and Figure 3(b)). The patient was decannulated on the fifth day. The nasogastric tube was removed on the 15th day. The resumption of normal food was marked by a few episodes of aspiration to liquids. After the result of the pathological examination, we perform a TSH-us assay (greater than $60 \mathrm{mIU} / \mathrm{l}$ ) which reveals hypothyroidism. Hormone replacement therapy was started immediately with 100 micrograms of levothyroxine. After two months, the healing was good and there were no more swallowing problems. The diagnosis of functional basilingual heterotopic goiter with a hypoplastic and non-functional thyroid gland was finally accepted.

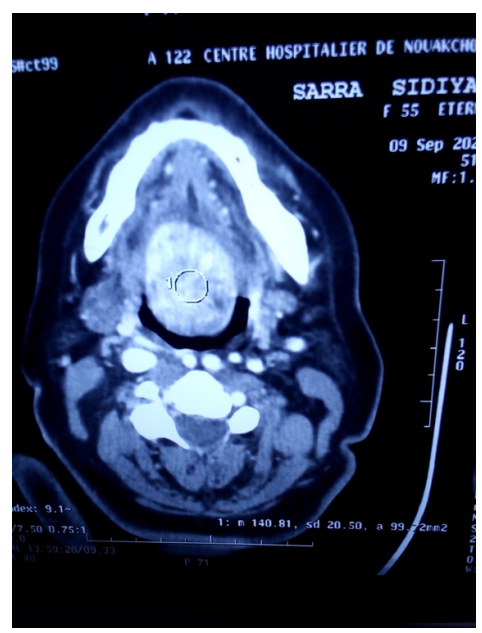

(a)

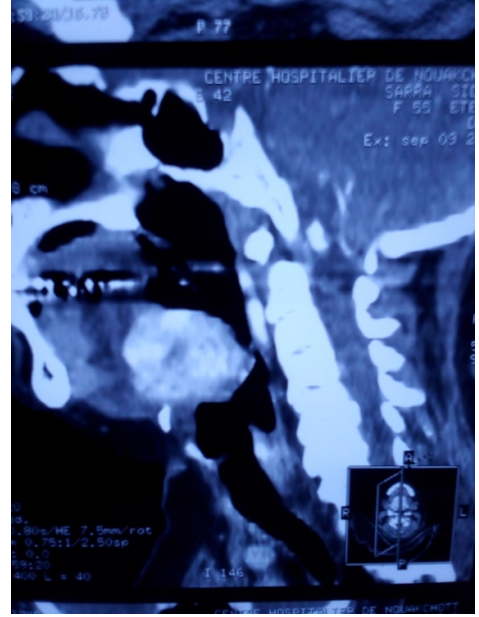

(b)

Figure 2. Cervical CT scan: Axial section (a) showing enhancement homogeneous tumor after injection of contrast product. Sagittal section (b): the well-defined mass, reducing the die of the oropharynx.

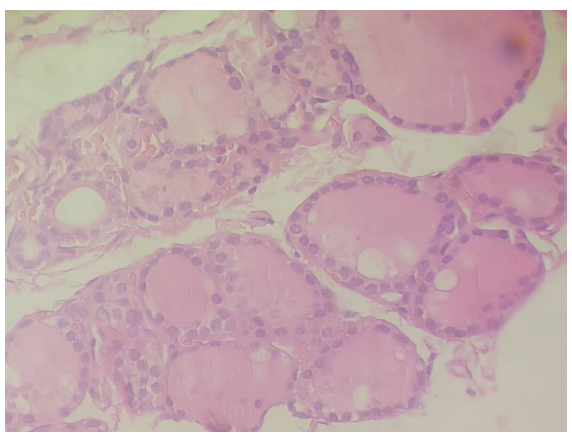

(a)

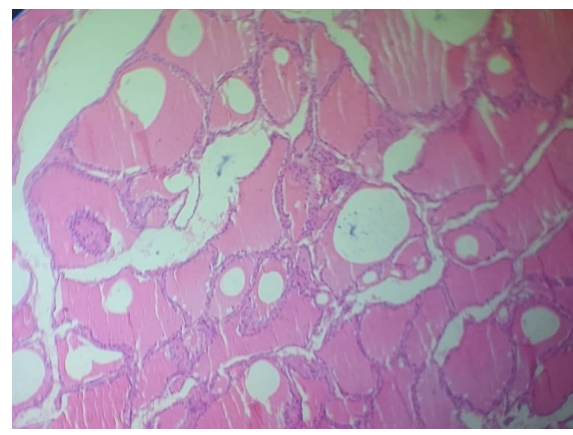

(b)

Figure 3. Lingual thyroid tissue. The thyroid follicles are filled with colloid material and lined by a cuboidal epithelium without atypia (hematoxylin and eosin, 200). (a) from first anatomopathologist; (b) from second one. 


\section{Discussion}

Ectopia and heterotopia are due to abnormalities in the maturation of thyroid tissues. Thyroid ectopy is a rare developmental abnormality involving abnormal embryogenesis during migration of the thyroid tubercle from the floor of the primary foregut to its final position in the neck [1] [2] [3] [4], facing the anterolateral aspect of the second to the fourth tracheal cartilage. Heterotopia is an abnormal localization of normal tissues coexisting with a normal organ and of normal localization [8] that must be differentiated with cancer metastasis. The pathogenesis of this dysembryogenesis is still unclear although Van der Gaag et al. [9] postulated that maternal antithyroid immunoglobulins inhibit the production of thyroid stimulating hormones and impair thyroid growth and migration. The frequency of ectopia of the thyroid gland in autopsy studies ranges from $7 \%$ to $10 \%$ [10] [11]. Ectopic locations can be submandibular, tracheal, lateral cervical, carotid, esophageal, gastric, duodenal, pancreatic, mesenteric, intracardiac, aortic, pulmonary, pituitary, axillary, and at the level of the iris of the eye. But lingual thyroid ectopia accounts for $90 \%$ of abnormalities [12] [13]. The age of discovery of ectopia or heterotopia of the thyroid gland is variable and depends on the clinical manifestation. According to Oueslati $S$ et al., the average age of discovery is 40 years with two peaks at 12 and 50 years with a clear predominance of women [1]. Our patient was 58 years old female patient.

The most common complaints observed during lingual thyroid ectopia are dysphagia, dysphonia, dyspnea, pain and cough [14]. In our case, the primary complaint was solids dysphagia. This obstructive symptomatology develops slowly and worsens, especially, during puberty or pregnancy [15]. Our patient's symptoms developed over 12 months. Signs of dysthyroidism, especially hypothyroidism, may appear during puberty, pregnancy, or other medical conditions. There is a risk of degeneration with metastatic dissemination [15] [16]. Such are not in our case. Cases of thyroid heterotopia have been reported [17] [18] [19].

Thyroid heterotopia is a simple or compound tissue of thyroid origin that can organize to form an entire organ anywhere in the body where it would not normally be. Functionally, the heterotopic gland can secrete hormones like a true thyroid gland [20]. In our case, it would be a basilingual thyroid heterotopia behaving like a real gland. This heterotopia develops latently, or presents as a tumor [21]. It is often discovered incidentally during a scintigraphic examination with iodine-131 or technetium- $99 \mathrm{~m}$ of a thyroid gland with functional disorders [13]. In our patient the scintigraphy was not performed because the cervical ultrasound had shown a thyroid gland in an anterior cervical position with a normal initial thyroid function. Only the pathological examination of a biopsy or an operative specimen confirms the thyroid origin of the swelling and makes it possible to eliminate a cancerous metastasis of thyroid origin. This made it difficult to relate the basilingual swelling with the thyroid gland, before the pathological result to confirm the heterotopia. Histological examination of the excisional biopsy revealed the thyroid origin with the appearance of heteronodular goiter without any sign of malignancy. 
The treatment of symptomatic basilingual goiters is surgical. It is associated with the medical treatment of a possible thyroid dysfunction. The surgical approach can be intrabuccal, cervical supra-hyoid or a combination of the two approaches. In our case, the anterior suprahyoid approach was performed. Nasotracheal intubation was performed. In case of doubt, a preoperative tracheostomy to avoid respiratory distress due to ptosis can be done; hematoma or bleeding of lingual origin may be seen [13]. Postoperative feeding by nasogastric tube reduces the risk of aspiration.

\section{Conclusion}

Sublingual thyroid heterotopia with functional thyroid tissue is exceptional. The reported case poses a diagnostic problem in front of a tumor of the base of the tongue. Despite their anatomy clinical diversity, lesions at the base of the tongue have common characteristics: dysphagia, dysphonia, pain and/or swelling. These clinical manifestations are not specific, paraclinical investigations such as imaging are necessary. The scintigraphy and the ultrasound are very powerful in the positive diagnosis. The formal diagnosis is histological after biopsy or resection of the lesion.

\section{Consent}

Oral and written consent has been obtained from the patient for publication of this case report and accompanied images.

\section{Conflicts of Interest}

The authors declare no conflicts of interest regarding the publication of this paper.

\section{References}

[1] Basaria, S., Westra, W.H. and Cooper, D.S. (2001) Ectopic Lingual Thyroid Masquerading as Thyroid Cancer Metastases. Journal of Clinical Endocrinology and Metabolism, 86, 392-395. https://doi.org/10.1210/jcem.86.1.7130

[2] Oueslati, S., Douira, W., Charada, L., Sa1d, W., Mlika, N., Rezgui, L., et al. (2006) Thyroide ectopique. Annales d Otolaryngologie et de Chirurgie Cervico-faciale, 123, 195-198. https://doi.org/10.1016/S0003-438X(06)76665-8

[3] Feller, K.-U., Mavros, A. and Gaertner, H.-J. (2000) Ectopic Submandibular Thyroid Tissue with a Coexisting Active and Normally Located Thyroidgland: Case Report and Review of Literature. Oral Surgery, Oral Medicine, Oral Pathology, Oral Radiology, and Endodontology, 90, 618-623. https://doi.org/10.1067/moe.2000.108804

[4] Guerra, G., Cinelli, M., Mesolella, M., et al. (2014) Morphological, Diagnostic and Surgical Features of Ectopic Thyroid Gland: A Review of Literature. International Journal of Surgery, 12, S3-S11. https://doi.org/10.1016/j.ijsu.2014.05.076

[5] Di Benedetto, V. (1997) Ectopic Thyroid Gland in the Submandibular Region Simulating a Thyroglossal Duct Cyst: A Case Report. Journal of Pediatric Surgery, 32, 1745-1746. https://doi.org/10.1016/s0022-3468(97)90522-4 
[6] Babazade, F., Mortazavi, H., Jalalian, H. and Shahvali, E. (2009) Thyroid Tissue as a Submandibular Mass: A Case Report. Journal of Oral Science, 51, 655-657. https://doi.org/10.2334/josnusd.51.655

[7] Herinirina, N.F., Rajaonarison, N.O., Rafanomezantsoa, H., Rakotoarisoa, A.J.C. and Ahmad, A. (2015) Une observation d'un goitre sur dysgénésie thyroïdienne pré-sternale. Pan African Medical Journal, 21, Article 117. https://doi.org/10.11604/pamj.2015.21.117.6919

[8] Van der Gaag, R.D., Drexhage, H.A. and Dussault, J.H. (1985) Role of Maternal Immunoglobulins Blocking TSH-Induced Thyroid Growth in Sporadic Forms of Congenital Hypothyroidism. The Lancet, 1, 245-250.

https://doi.org/10.1016/S0140-6736(85)91028-1

[9] Kousta, E., Konstantinidis, K., Michalakis, C., Vorias, M., Sambalis, G., Georgiou, M., et al. (2005) Ectopic Thyroid Tissue in the Lower Neck with a Coexisting Normally Located Multinodular Goiter and Brief Literature Review. Hormones, 4, 231-234. https://doi.org/10.14310/horm.2002.11163

[10] Bersaneti, J.A., Silva, R.D., Ramos, R.R., Matsushita Mde, M. and Souto, L.R. (2011) Ectopic Thyroid Presenting as a Submandibular Mass. Head and Neck Pathology, 5, 63-66. https://doi.org/10.1007/s12105-010-0209-Z

[11] Neinas, F.W., Gorman, C.A., Devine, K.D. and Woolner, L.B. (1973) Lingual Thyroid. Clinical Characteristics of 15 Cases. Annals of Internal Medicine, 79, 205-210. https://doi.org/10.7326/0003-4819-79-2-205

[12] Toso, A., Colombani, F., Averono, G., Aluffi, P. and Pia, F. (2009) Lingual Thyroid Causing Dysphagia and Dyspnoea. Case Reports and Review of the Literature. Otorhinolaryngologica Italica, 29, 213-217.

[13] Tincani, A.J., Martins, A.S., Del Negro, A., Araújo, P.P. and Barretto, G. (2004) Lingual Thyroid Causing Dysphonia: Evaluation and Management. Case Report. Sao Paulo Medical Journal, 122, 67-69. https://doi.org/10.1590/S1516-31802004000200007

[14] Marzouki, H.Z., Aldajani, A., Merdad, M., Saber, W. and Amer, I. (2020) Papillary Microcarcinoma of Sublingual Thyroid Gland: A Case Report. Cureus, 12, e6810.

[15] Kao, S.-Y., Tu, H.-F., Chang, R.C.-S., Yang, A.-H., Chang, K.-W. and Lee, C.-H. (2002) Primary. Ectopic Thyroid Papillary Carcinoma in the Floor of the Mouth and Tongue: A Case Report. British Journal of Oral and Maxillofacial Surgery, 40, 213-215. https://doi.org/10.1054/bjom.2001.0686

[16] Huang, T.-S. and Chen, H.-Y. (2007) Dual Thyroid Ectopia with a Normally Located Pretracheal Thyroid Gland: Case Report and Literature Review. Head \& Neck, 29, 885-888. https://doi.org/10.1002/hed.20604

[17] Ulug, T., Ulubil, S.A. and Alagol, F. (2003) Dual Ectopic Thyroid: Report of a Case. The Journal of Laryngology \& Otology, 117, 574-576. https://doi.org/10.1258/002221503322113076

[18] Hazarika, P., Siddiqui, S.A., Pujary, K., Shah, P., Nayak, D.R. and Balakrishnan, R. (1998) Dual Ectopic Thyroid: A Report of Two Cases. The Journal of Laryngology \& Otology, 112, 393-395. https://doi.org/10.1017/S0022215100140563

[19] Le Roux, B.T. (1961) Heterotopic Mediastinal Thyroid. Thorax, 16, 192-196. https://doi.org/10.1136/thx.16.2.192

[20] Dechelotte, P. and Delezoïde, A. (2005) Pathologie du développement-Malformations congénitales. AFECAP, Google Scholar.

[21] Baron, L. (1994) Ectopic Thyroid Simulating a Mass: Imaging Finding. American Journal of Roentgenology, 162, 643-647. https://doi.org/10.2214/ajr.162.3.8109514 